\title{
ADESÃO AO TRATAMENTO HEMODIALÍTICO: PERCEPÇÃO DOS PACIENTES RENAIS CRÔNICOS*
}

\author{
Camilla de Godoy Maciel1', Rafaela Novaes Ferraz², Vanessa Vieira França³, Iracema da Silva Frazão ${ }^{4}$, Anna Karla de Oliveira
}

${ }^{1}$ Enfermeira. Especialista em Nefrologia. Hospital Barão de Lucena. Recife, PE, Brasil.

Tito Borba ${ }^{5}$

${ }^{2}$ Enfermeira. Especialista em Nefrologia. Hospital Barão de Lucena. Recife, PE, Brasil.

${ }^{3}$ Enfermeira. Mestranda em Enfermagem. Universidade Federal de Pernambuco. Recife, PE, Brasil.

${ }^{4}$ Enfermeira. Doutora em Serviço Social. Docente do Departamento de Enfermagem da Universidade Federal de Pernambuco. Recife, PE, Brasil.

${ }^{5}$ Enfermeira. Mestre em Enfermagem. Docente do Departamento de Enfermagem da Universidade Federal de Pernambuco. Recife, PE, Brasil.

RESUMO: Estudo descritivo, exploratório, de abordagem qualitativa que objetivou identificar fatores que interferem na adesão ao tratamento hemodialítico na percepção dos pacientes renais crônicos. Participaram 35 pacientes assistidos por um serviço público de hemodiálise em uma capital do Nordeste do Brasil, com coleta das informações entre maio e agosto de 2014. As informações foram coletadas por meio de questionário semiestruturado e analisadas pelo software ALCESTE. Os principais fatores que influenciaram na adesão foram: dificuldade de transporte, déficit de conhecimento sobre a doença, limitações do tratamento, transtornos vivenciados nas sessões de hemodiálise, controle das taxas pelos exames laboratoriais, fé, máquina de hemodiálise e suporte social. Considera-se, portanto, que os fatores que interferem na adesão são complexos, tornando-se necessária atuação multidisciplinar para a compreensão desse fenômeno e o desenvolvimento de estratégias educativas com vistas à conscientização dos indivíduos sobre a importância da adesão ao tratamento e possível melhoria da qualidade de vida.

DESCRITORES: Insuficiência renal crônica; Diálise renal; Cooperação do paciente.

\section{ADHERENCE TO HEMODIALYSIS TREATMENT: THE PERCEPTION OF CHRONIC RENAL PATIENTS}

\begin{abstract}
This descriptive exploratory study, with a qualitative approach, aimed to identify factors which influence adherence to hemodialysis treatment in the perception of chronic renal patients. A total of 35 patients participated, who were assisted by a public hemodialysis service in a state capital in the Northeast of Brazil, with data collection taking place between May and August 2014 The information was collected through a semistructured questionnaire and was analyzed using the ALCESTE software. The main factors that influence adherence were: transport difficulties, deficit of knowledge regarding the illness, limitations of the treatment, problems experienced in the hemodialysis sessions, control of the rates through laboratory examinations, religious faith, the hemodialysis machine, and social support. It is considered, therefore, that the factors influencing adherence are complex, making it necessary to undertake multi-professional activity in order to understand this phenomenon, and to develop educational strategies with a view to raising individuals' awareness regarding the importance of adherence to the treatment and possible improvement in quality of life.
\end{abstract}

DESCRIPTORS: Chronic renal failure; Renal dialysis; Patient cooperation.

\section{ADHESIÓN AL TRATAMIENTO HEMODIALÍTICO: PERCEPCIÓN DE LOS PACIENTES RENALES CRÓNICOS}

RESUMEN: Estudio descriptivo, exploratorio, de abordaje cualitativo cuyo objetivo fue identificar factores que influyen en la adhesión al tratamiento hemodialítico en la percepción de los pacientes renales crónicos. Participaron 35 pacientes asistidos por un servicio público de hemodiálisis en una capital de Nordeste de Brasil. La obtención de las informaciones ocurrió entre mayo y agosto de 2014. Las informaciones fueron recogidas por medio de cuestionario semiestructurado y analizadas por el software ALCESTE. Los principales factores que influenciaron en la adhesión fueron: dificultad de transporte, déficit de conocimiento sobre la enfermedad, limitaciones del tratamiento, trastornos en las sesiones de hemodiálisis, control de las tajas por los exámenes de laboratorio, fe, máquina de hemodiálisis y apoyo social. Se considera, por lo tanto, que los factores que influyen en la adhesión son complejos, siendo necesaria actuación multidisciplinar para la comprensión de ese fenómeno y el desarrollo de estrategias educativas para concienciar los individuos acerca de la importancia de la adhesión al tratamiento y posible mejoría de la cualidad de vida.

DESCRIPTORES: Insuficiencia Renal Crónica; Diálisis Renal; Cooperación del Paciente.

*Artigo extraído do Trabalho de Conclusão de Curso de Residência: “Adesão ao tratamento hemodialítico: percepção dos pacientes renais crônicos". Programa de Residência de Enfermagem em Nefrologia do Hospital Barão de Lucena, 2015. 


\section{INTRODUÇÃO}

A Doença Renal Crônica (DRC) é considerada uma epidemia mundial devido à sua prevalência alarmante e a taxa de morbimortalidade elevada, com destaque para as transformações socioeconômicas, físicas e psicológicas que desencadeia na vida do indivíduo ${ }^{(1)}$.

A National Kidney Foundation (NKF) conceitua a DRC, em seu documento Kidney Disease Outcomes Quality Initiative (K/DOQI), como uma lesão do parênquima renal por um período igual ou superior a três meses, evidenciada por proteinúria e/ou hematúria e/ou Ritmo de Filtração Glomerular (RFG) inferior a $60 \mathrm{ml} / \mathrm{min} / 1,73 \mathrm{~m}^{(2)}$.

De acordo com o Censo Brasileiro de Diálise de 2013, estima-se que 100.397 pacientes estão inclusos no programa de diálise, sendo 90,8\% em tratamento por Hemodiálise (HD) e 9,2\% por Diálise Peritoneal (DP) ${ }^{(3)}$.

A HD tem como finalidade remover do sangue as excretas nitrogenadas e o excesso de líquido por meio de uma membrana semipermeável denominada dialisador. No entanto, esse processo gera uma série de fatores estressantes ao portador de DRC, como alterações metabólicas e endócrinas, alterações na percepção da autoimagem e mudanças no estilo de vida, sendo considerados obstáculos para a adesão ao tratamento hemodialítico ${ }^{(4)}$.

A adesão é considerada um processo em que o sujeito atende às expectativas do tratamento proposto, ao seguir as orientações e prescrições recomendadas pela equipe multiprofissional. É vista como um artifício a ser utilizado para a melhoria do quadro clínico dos usuários ${ }^{(5)}$.

Dessa maneira, o conhecimento dos fatores que envolvem a adesão ao tratamento hemodialítico é imprescindível. A aceitação da doença e o reconhecimento da importância do tratamento proposto leva o cliente a seguir as recomendações dadas pelos profissionais e, assim, reduzir as complicações da DRC e melhorar as condições clínicas. Além disso, confere maior autonomia ao indivíduo na busca de alternativas de superação das dificuldades e a possibilidade de adaptar-se à nova condição de saúde ${ }^{(6)}$.

Considerando as dificuldades encontradas pelos pacientes renais crônicos em aderirem ao tratamento hemodialítico e a complexidade de fatores envolvidos nessa problemática, este estudo teve como objetivo identificar os fatores que interferem na adesão ao tratamento hemodialítico na percepção dos pacientes renais crônicos.

\section{MÉTODO}

Trata-se de um estudo descritivo, exploratório, com abordagem qualitativa, realizado no serviço de HD de um hospital público de referência estadual em nefrologia localizado na cidade de Recife, estado de Pernambuco. Participaram indivíduos portadores de DRC em tratamento hemodialítico cadastrados na unidade, por no mínimo, 12 meses. Foram excluídos aqueles com comprometimento de comunicação ou cognição, pacientes em trânsito (usuários cadastrados em outras clínicas, realizando HD temporariamente no serviço) e aqueles internados na Unidade de Terapia Intensiva (UTI) durante o período da coleta das informações. A amostra foi de 35 pacientes renais crônicos do serviço.

A coleta das informações ocorreu no período de maio a agosto de 2014 através de entrevista semiestruturada, em local reservado, antes do início do tratamento hemodialítico. O instrumento de coleta foi composto por dados sociodemográficos e situação clínica, como sexo, faixa etária, estado civil, escolaridade, ocupação, doença de base, tempo de HD e o tipo de acesso vascular. Além desses, foram incluídas duas questões norteadoras: $O$ que o senhor(a) sabe sobre a sua doença? Quais os fatores que interferem positivamente e negativamente na adesão ao tratamento hemodialítico?

As entrevistas gravadas foram transcritas e analisadas através do programa Analyse Lexicale par Contexte d'um Ensemble de Segments de Texte (ALCESTE), versão 2010. Esse software apresenta uma organização dos dados, por meio de análises estatísticas e matemáticas, ao fornecer o número de classes, as relações existentes entre elas, as divisões realizadas com o material até a formação das classes, as formas radicais e palavras associadas aos seus respectivos valores do qui-quadrado, além do contexto semântico de cada classe ${ }^{(7)}$.

O estudo foi submetido e aprovado pelo Comitê de Ética em Pesquisa da Fundação de Ensino Superior de Olinda através do CAAE 28328914.5.0000.5194. Foram respeitados os preceitos éticos estabelecidos para pesquisas envolvendo seres humanos, em concordância com a Resolução 466/12(8). 


\section{RESULTADOS}

Dos 35 pacientes participantes do estudo, predominou o sexo masculino (66\%), com mais de 60 anos (40\%) e de 46 a 60 anos $(40 \%)$, casados ou em união estável $(51,43 \%)$, ensino fundamental incompleto $(40 \%)$ e analfabetos $(29 \%)$. Destaca-se a vultosa presença de pacientes que recebiam benefício decorrente da doença $(86 \%)$ se comparados àqueles que exerciam alguma atividade remunerada (11\%).

No tocante à doença de base, a maioria dos participantes não tinha etiologia definida para a DRC (29\%). A associação da Hipertensão Arterial Sistêmica (HAS) e Diabetes Mellitus (DM) foi a principal causa (23\%), seguida de HAS $(20 \%)$, outras causas como litíase renal, uropatia obstrutiva, bexiga neurogênica e nefrocalcinose (14\%), DM (11\%) e glomerulonefrite crônica (3\%).
Verificou-se que $63 \%$ dos pacientes estavam inseridos no programa de HD por um período de 1 a 3 anos, 86\% apresentou como acesso para a realização da HD a fístula arteriovenosa (FAV) e $11 \%$ dialisava com cateter.

A partir do discurso dos entrevistados, foram originadas e transcritas 35 entrevistas que geraram as Unidades de Contexto Elementares (UCEs) e que correspondem às classes de palavras com maior frequência no texto bruto (corpus) e maior valor do qui-quadrado de associação dessas palavras às classes(9). Das falas dos participantes, foram geradas 187 UCEs que após a análise por meio do Método de Análise da Classificação Hierárquica Descendente obteve-se um aproveitamento de $62 \%$ dessas unidades (116). Essas UCEs foram reagrupadas de acordo com suas semelhanças lexicais formando 5 classes temáticas, ordenadas de acordo com sua associação estatística e

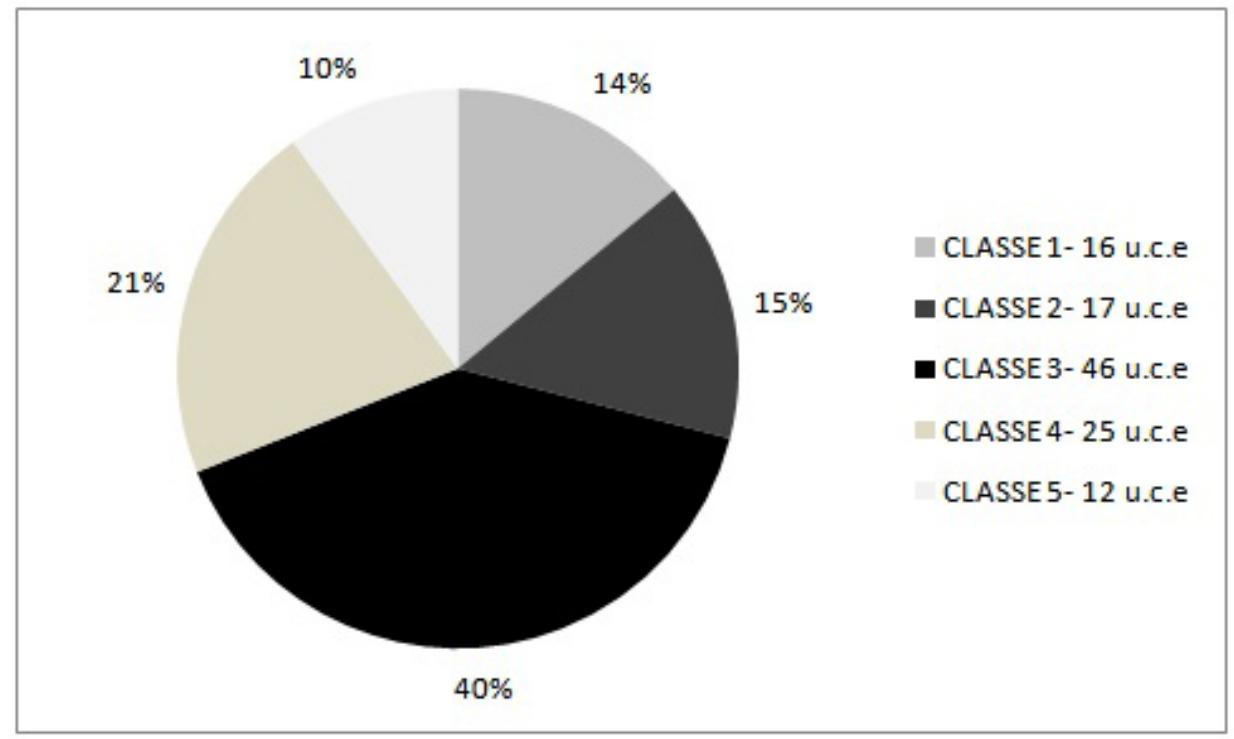

Figura 1- Distribuição de UCEs classificadas segundo o discurso de pacientes em tratamento hemodialítico. Recife, 2015

representatividade numérica (percentual de UCEs utilizadas) (Figura 1).

Classe 1: Dificuldade de transporte ao serviço de diálise

Os pacientes relataram a dificuldade de acesso ao transporte para o centro de HD. Essa dificuldade é ocasionada pelo custo financeiro com o deslocamento e a falta de comprometimento da prefeitura quanto à disponibilidade do veículo, como observado nas falas a seguir:

O que atrapalha mais pra vim só é o carro pra me trazer, eu estava pagando muito caro o carro. Quem está me trazendo agora é o meu genro [...]. (Sujeito 8)
Primeiro ponto negativo é o transporte da prefeitura que traz a gente, é péssimo. Tem dias que traz a gente e tem dias que não traz. Com isso, a gente se sacrifica porque alguns vêm de ônibus, outros alugam um carro e isso já mexe com a mente. Pode ver que todos chegam alterados e com a pressão alterada. (Sujeito 28)

Tenho a dificuldade do transporte, antigamente eu vinha no carro da prefeitura e agora eu venho de ônibus por opção minha. (Sujeito 32)

Classe 2: Fatores facilitadores no processo da adesão e manutenção do tratamento

Os fatores elencados pelos participantes como facilitadores para a promoção da adesão ao 
tratamento abrangem tanto os aspectos ligados à terapêutica quanto os espirituais. Dentre os componentes relacionados à terapia, destacam-se os exames laboratoriais para o acompanhamento da doença e a realização da HD, na qual a máquina é vista como meio de sobrevivência e de alívio dos sintomas decorrentes da enfermidade, conforme os discursos abaixo:

Eu vivo muito doente, o que ajuda é fazer os exames para acompanhar essa doença [...]. (Sujeito 6)

Eu comecei a adoecer, comecei a ficar fraca e fui pra médica que passou exames, quando saiu o resultado deu que eu tinha isso [...]. (Sujeito 13)

Aqui é bom pra mim, eu estou sem urinar e quando eu faço a hemodiálise eu fico bem e durmo bem. (Sujeito 16)

Ah, o tratamento agora tem muita coisa boa, depois que essa doutora passou a fazer exames em mim, ela diminuiu meus dias, porque eu vinha pra máquina três vezes por semana, aí agora ela diminuiu os dias, eu só venho duas vezes. (Sujeito 20)

Outro elemento que emergiu da análise foi o papel da espiritualidade no encorajamento à execução do plano terapêutico. A "fé em Deus" pode ser identificada no discurso abaixo como um elemento motivador para a continuidade do tratamento e aceitação das recomendações.

Se eu deixar de fazer a hemodiálise, eu estou liquidado. É difícil, mas com a fé que eu tenho em Deus, eu vou em frente. (Sujeito 2)

Classe 3: Déficit de conhecimento como preditor da progressão da doença renal

Os participantes do estudo mostraram ter pouco conhecimento acerca de sua patologia, limitando-se apenas ao discernimento das causas subjacentes ao problema renal e a um entendimento superficial sobre a doença. $\mathrm{O}$ conhecimento mostrou-se restrito às consequências da DRC e às limitações impostas pelo tratamento no tocante à dieta e à ingesta hídrica.

Eu não sei de nada, só sei que a médica disse que foi por causa da pressão. Mas eu nunca me interessei em saber de nada não. Que não pode comer isso, aquilo, aquilo outro, muitas coisas. Não pode beber muita água, não podem muitas coisas. (Sujeito 5)

Sei que é por causa da diabetes e da pressão alta, porque era muito alta minha pressão e minha diabetes. (Sujeito 8)
É uma doença que eu não posso mais fazer xixi, que eu não consigo mais fazer xixi e é só isso. (Sujeito 9)

A minha doença não foi provocada pela diabetes, foi provocada pela pressão. Era um troço que eu não sabia nem o que era e eu tomava bastante água. (Sujeito 25)

\section{Classe 4: Sala de hemodiálise: um cenário de troca de experiências}

A interação dos doentes renais crônicos com outros pacientes, familiares e a equipe multiprofissional proporciona a troca de vivências e de saberes que constitui um verdadeiro instrumento de barganha de conhecimentos acerca da doença e do tratamento. Os clientes afirmam nas interlocuções, que a sala de HD é um ambiente de solidariedade que propicia o compartilhamento de experiências adquiridas e de sugestões para a melhoria do seguimento terapêutico, o que contribui para auxiliar no processo de enfrentamento da doença e tratamento.

O que contribui é a consciência de todos me ajudando, o apoio dos familiares para que eu cumpra a dieta, o convívio com os outros pacientes com o mesmo problema meu, a atenção também por parte dos funcionários no tratamento [...]. (Sujeito 1)

As pessoas que trabalham aqui falam, eles conversam muitas coisas e a gente tem que aceitar, eles ajudam muito. Dão conselho, falam o que a pessoa tem que fazer; tudo isso. (Sujeito 5)

O que eu sei são algumas coisas que a gente aprende uns com os outros e eu aprendi com os amigos. (Sujeito 15)

Classe 5: Rotinas de uma sessão de hemodiálise como limitante da satisfação com o tratamento

A HD, apesar dos seus múltiplos benefícios, é considerada um tratamento doloroso pelos utentes. A rotina das sessões e a mudança no estilo de vida são vistos como pontos negativos na terapia por limitar a satisfação com o tratamento. Os relatos dos participantes do estudo expõem a existência de vários fatores estressores envolvidos no seu cotidiano, como podem ser visualizados nos depoimentos abaixo:

Não posso comer tudo que eu comia. Tudo é controlado e isso é ruim. (Sujeito 22)

Só acho ruim porque eu não posso tomar água, tomo pouquinha água. (Sujeito 23)

O que existe de ruim no tratamento é essa posição 
que a gente fica aqui nas quatro horas sem poder se mexer, não é coisa boa. (Sujeito 24)

Às vezes a gente se agita, mas tem que aguentar passar aquelas quatro horas lá. Eu vou dizer uma coisa a você, só o que me dificulta mais são as furadas das agulhas que eu não aguento, arde um pouco. (Sujeito 25)

\section{DISCUSSÃO}

A população masculina, os idosos e adultos em transição (46 a 60 anos) foram grupos prevalentes neste estudo, estando de acordo com o Censo Brasileiro de Diálise de $2013^{(3)}$. A maioria dos participantes da pesquisa tinha relacionamento conjugal, baixo grau de instrução e recebiam benefício auxílio-doença. Estudo semelhante em oito centros de diálise no Maranhão, com 330 pacientes com DCR em HD corrobora esses dados, em que $59,6 \%$ eram casados, $56,7 \%$ tinham baixa escolaridade e $49,1 \%$ recebiam benefício por doença ${ }^{(10)}$.

O Inquérito Brasileiro de Diálise, publicado pela Sociedade Brasileira de Nefrologia (SBN) divulga como principais causas da DRC a HAS, o DM e as glomerulonefrites, respectivamente ${ }^{(3)}$. Neste estudo, a maior parte dos usuários não tinha causa determinada para a afecção renal, sendo justificada pela presença de diversas comorbidades, dificultando assim a definição do diagnóstico. A participação mútua da HAS e da DM também teve ênfase, uma vez que são as doenças de base com maior impacto na fisiopatologia renal.

Apesar do número crescente de indivíduos em HD, ocorre também a migração dessa modalidade para DP e transplante renal(11), podendo explicar a redução de pacientes inseridos em HD há um maior tempo nesta investigação. A prevalência da FAV como acesso vascular se deve ao fato da pesquisa ser composta por pacientes renais crônicos inseridos em HD, no mínimo há um ano, tempo suficiente para a confecção e maturação do respectivo acesso.

Das classes emergidas, a dificuldade de transporte ao serviço de diálise foi um dos fatores identificados como obstáculo na adesão ao tratamento. $\mathrm{O}$ impacto socioeconômico decorrente da DRC afeta o seio familiar, pois a limitação física subsequente à enfermidade tornase um empecilho para a locomoção e o trabalho. Dessa forma, um número considerável de pessoas acometidas pela doença renal abandonam seus empregos para viver com a renda do auxílio-

\section{doença ${ }^{(12)}$.}

O transporte é uma causa importante de faltas e atrasos na HD, visto que os clientes renais queixam-se da dificuldade financeira para custear o translado ao centro hemodialítico(5). Estudo realizado em uma clínica de HD, no município de Petrópolis, estado do Rio de Janeiro, atesta que a distância entre o local de tratamento e a residência dos usuários, bem como a deficiência na rede de serviços de transporte são fatores estressantes para o indivíduo e os familiares, culminando na quebra do regime terapêutico ${ }^{(13)}$.

É conhecida a responsabilidade do Estado em ofertar transporte público, gratuito com qualidade e segurançaàs pessoas portadoras denecessidades especiais, como meio de garantir a integralidade do cuidado desse grupo vulnerável ${ }^{(14)}$. Apesar dos municípios disponibilizarem esse serviço, um número considerável de sujeitos não se beneficia desse direito, ao levar em consideração que alguns pacientes utilizaram outros meios de locomoção, tais como bicicleta, táxis e carros alugados. Isso mostra a lacuna existente na prestação de serviços públicos, em que o usuário prejudica-se pela qualidade questionável dos meios de transporte públicos.

O componente exame laboratorial mostrouse como um recurso de auxílio na terapia, servindo de parâmetro para orientar o médico quanto à redução nas horas de diálise e nas sessões quando indicados, assim os pacientes são incentivados a realizarem o tratamento com o intuito de melhoria do quadro. Pôde-se observar também o papel fundamental dos exames na descoberta e controle da doença, propiciando a implementação do tratamento necessário.

Estudo desenvolvido em Hospital Universitário do Rio Grande do Sul destaca a importância dos exames laboratoriais para detectar alterações clínicas tais como acidose metabólica, hipercalemia, hiperfosfatemia, dentre outras, mostrando que esses parâmetros podem influenciar na adesão terapêutica ao identificar a causa básica de diversos problemas e possibilitar a intervenção para o alívio de sintomas e otimização da situação clínica ${ }^{(6)}$.

É imprescindível o acompanhamento laboratorial na patologia renal com a finalidade de monitorar a progressão da doença e identificar precocemente complicações secundárias, visto a diversidade de alterações metabólicas causadas pela função renal deteriorada(15). 
A máquina de HD foi vista como ponto crucial do tratamento, fonte de bem-estar e recurso ímpar para atenuação das manifestações clínicas da doença. Por outro lado, apesar de haver o reconhecimento de sua importância, os pacientes consideravam-se reféns de uma máquina atrelada a um tratamento obrigatório e doloroso que traz mudanças repentinas e limitações em suas vidas.

Estudo qualitativo sobre a percepção e a qualidade de vida de pacientes submetidos à $\mathrm{HD}$, realizado em um centro nefrológico no Rio Grande do Sul com nove pacientes, encontrou resultados semelhantes ao identificar a HD como a esperança de uma sobrevida com autonomia e qualidade, enquanto aguarda a realização de um possível transplante. Porém, foi ressaltado que o tratamento gerava uma duplicidade de sentimentos, fragmentando a percepção dos indivíduos acerca da terapia, pois ao mesmo tempo em que a máquina era percebida como item essencial para a preservação de suas vidas, também significava dependência, medo da morte, sofrimento e sensação de aprisionamento ${ }^{(16)}$.

Quanto à presença de elementos relacionados à terapia, a fé foi vista como incentivadora para a continuidade terapêutica. Este é um baluarte no enfrentamento de momentos críticos, tal como a descoberta de uma doença, servindo de conforto e amparo, além de trazer benefícios importantes à saúde, com melhoria no âmbito psicossocial, físico e espiritual por incentivar a realização do tratamento ${ }^{(17)}$.

Estudo sobre a espiritualidade desenvolvido em dois serviços nefrológicos de João Pessoa, estado da Paraíba, com 100 pacientes portadores de DRC inseridos em HD, revelou que a fé modifica positivamente a concepção do sujeito a respeito de sua doença e da sua vida, bem como a sua maneira de agir, contribuindo para a adesão e a reabilitação ${ }^{(18)}$. Portanto, cabe ao profissional de saúde um olhar diferenciado para essa particularidade, pelo significado que ela representa para o paciente, caracterizada como uma necessidade humana básica.

O déficit de conhecimento como preditor na progressão da doença renal foi a classe numericamente mais representativa do estudo. A carência de informação sobre a doença e o tratamento pode ser um reflexo do baixo nível socioeconômico e da escolaridade da amostra em questão, uma vez que os usuários mostraram dificuldade em definir os aspectos citados.

Outro ponto relevante foi o desconhecimento da importância do controle da HAS e da DM para prevenção da progressão da DRC. É conhecida a participação das doenças de base no desenvolvimento desta patologia, havendo deficiência em trabalhos preventivos com grupos populacionais de risco. Essa realidade brasileira mostra a necessidade de enfoque maior na educação em saúde visando à redução da incidência das doenças crônicas ${ }^{(19)}$.

Sabe-se que o déficit de conhecimento influencia negativamente no processo de autocuidado, pois clientes com baixa instrução têm dificuldade de compreender as recomendações dadas, obtendo maior índice de abandono ao tratamento. Além disso, eles apresentam dificuldades na prevenção de suas comorbidades, o que influencia na descoberta tardia da doença impedindo uma abordagem precoce e redução de complicações ${ }^{(10)}$.

As classes sociais desfavorecidas apresentam fragilidade no conhecimento, dificultando assim a continuidade da terapia, tornando imprescindível a atuação diferenciada da equipe multidisciplinar para com eles, utilizando estratégias educativas contínuas com ênfase na promoção do conhecimento. Para isso é indispensável dispor de recursos que facilitem o entendimento tais como o uso de uma linguagem simples, folhetos ilustrativos, palestras e rodas de conversas ${ }^{(12)}$.

A existência de redes de apoio ao paciente renal crônico é essencial no suporte ao reconhecimento da doença, possibilitando uma nova concepção sobre a doença e a importância da HD para a sua nova forma de viver. O convívio do portador de DRC com seus familiares, assim como a interrelação estabelecida com os outros pacientes e os profissionais de saúde contribuem para ele adquirir atitudes positivas concernentes ao seu problema de saúde e tratamento ${ }^{(20)}$.

É visto que a DRC desestrutura a vida do paciente por alterar a sua forma de viver, desencadeando limitações físicas e psicossociais. Em consequência disso, inúmeros problemas secundários são percebidos como isolamento social, incapacidade para trabalhar, depressão, pessimismo e desistência do tratamento. Nesse momento, a presença da família e da equipe de saúde é fundamental para resgatar nos indivíduos a vontade de viver, a autoestima e o autocontrole no decurso da enfermidade ${ }^{(21)}$.

A equipe multidisciplinar compartilha responsabilidades com o usuário do serviço para formar uma "aliança terapêutica", na qual os 
profissionais de saúde têm a função de envolver o paciente e seus familiares num processo de adaptação, dirimindo as dúvidas e esclarecendo a importância da aderência à terapia para o bemestar e redução da mortalidade ${ }^{(22)}$.

É importante salientar que o ambiente de HD propicia a comunicação dos pacientes entre si. Essa relação de grupos é benéfica à adesão e ao enfrentamento das dificuldades vivenciadas. O vínculo formado entre os usuários permite a construção do saber acerca da doença e do tratamento, assim essa relação proporciona o aprendizado contínuo de uns com os outros potencializando a aderência terapêutica ${ }^{(23)}$.

As adversidades vivenciadas na HD são um fator limitante da satisfação com o tratamento. Desse modo, constata-se que a DRC requer tratamento rigoroso com a necessidade de mudanças radicais nos hábitos de vida impactando e restringindo a vida diária das pessoas ${ }^{(11)}$.

Desse modo, percebe-se que os doentes renais crônicos em HD lidam com situações estressantes desde a problemática advinda da rigorosidade em seguir às prescrições até as dores e o desconforto experimentados no ambiente do tratamento. A associação desses fatores contribui para baixa adesão, aumento de complicações e impacto negativo na qualidade de vida ${ }^{(22)}$.

O regime alimentar e hídrico se faz necessário pelas alterações fisiológicas acarretadas pela DRC. Comumente os pacientes têm restrições no consumo de alimentos que contêm fósforo, potássio, sódio, proteínas e água, comprometendo o seu bem-estar e estilo de vida, o que desencadeia resistência em seguir esse controle. Outro problema bastante presente na patologia renal é o comprometimento ósseo e muscular que leva a dores intensas, fraqueza e mal-estar, sendo exacerbados pela ação da HD. Com isso, os indivíduos tendem a recusar a realização do tratamento temendo a ocorrência de complicações intradialíticas ${ }^{(24)}$.

A escuta ativa e o diálogo efetivo estabelecido entre profissional-paciente são os pilares para uma relação de confiança e sucesso no tratamento. A confiabilidade permite ao indivíduo explicitar suas angústias, dúvidas e crenças, e a partir disto o profissional apreende as dificuldades encontradas para elaborar estratégias que facilitem a adesão do sujeito ${ }^{(10)}$.

\section{CONSIDERAÇÕES FINAIS}

No presente estudo, constatou-se a presença de elementos que influenciaram tanto de modo positivo como negativo sobre a resposta do paciente ao tratamento. Os principais obstáculos mencionados foram a dificuldade de transporte justificado pelo baixo nível socioeconômico, o déficit de conhecimento acerca da doença, as limitações decorrentes do tratamento e os transtornos vivenciados nas sessões de HD. Já os aspectos motivadores à adesão terapêutica foram o convívio com a máquina de HD, a realização de exames laboratoriais, a fé e a presença de suporte social.

Diante do exposto, é notório destacar que a adesão constitui o ponto fundamental para o tratamento da DRC, atenuação de complicações e de eventos cardiovasculares no decorrer do plano terapêutico. Para tal, é preciso que os profissionais de saúde atuem nos fatores que influenciam a adesão com o propósito de compreender os fenômenos que levam à falha desse processo e no desenvolvimento de estratégias educativas com o intuito de conscientizar os indivíduos para a importância da adesão ao tratamento e possível melhoria da qualidade de vida.

\section{REFERÊNCIAS}

1. Santos RP, Rocha DLB, Koch VHK. Componentes clínico-epidemiológicos de crianças e adolescentes em hemodiálise. Cogitare enferm. [Internet] 2014; 19(2) [acesso em 02 jan 2015]. Disponível em: http:// dx.doi.org/10.5380/ce.v19i2.33924

2. National Kidney Foundation. K/DOQI clinical practice guidelines for chronic kidney disease: evaluation, classification, and stratification. Am J Kidney Dis. [Internet] 2002; 39(2) [acesso em 02 jan 2015]. Disponível: http://www.ncbi.nlm.nih.gov/ pubmed/11904577

3. Sociedade Brasileira de Nefrologia. Inquérito brasileiro de diálise crônica 2013- análise das tendências entre 2011 e 2013. J. Bras. Nefrol. [Internet] 2013; 36(4) [acesso em 08 jan 2015]. Disponível: http:// dx.doi.org/10.5935/0101-2800.20140068

4. Santos I, Rocha RPF, Berardinelli LMM. Necessidades de orientação de enfermagem para o autocuidado de clientes em terapia de hemodiálise. Rev. Bras. Enferm. [Internet] 2011; 64(2) [acesso em $22 \mathrm{dez}$ 2014]. Disponível: http://dx.doi.org/10.1590/S003471672011000200018

5. Dias AM, Cunha M, Santos AMM, Neves APG, Pinto AFC, Silva ASA, et al. Adesão ao regime terapêutico 
na doença crônica: revisão da literatura. Millenium. [Internet] 2011; 40 [acesso em 15 dez 2014]. Disponível: http://www.ipv.pt/millenium/Millenium40/14.pdf

6. Sgnaolin V, Figueiredo AEPL. Adesão ao tratamento farmacológico de pacientes em hemodiálise. J. Bras. Nefrol. [Internet] 2012; 34(2) [acesso em 11 jan 2015]. Disponível: http://dx.doi.org/10.1590/S010128002012000200002

7. Gomes AMT, Oliveira DC. Autonomia profissional em um desenho atômico: representações sociais de enfermeiros. Rev. Bras. Enferm. [Internet] 2010; 63(4) [acesso em 22 dez 2014]. Disponível: http://dx.doi. org/10.1590/S0034-71672010000400017

8. Ministério da Saúde (BR). Conselho Nacional de Saúde. Diretrizes e normas regulamentadoras de pesquisa envolvendo seres humanos. Resolução n. 466, de 12 de dezembro de 2012. Brasília; 2012.

9. Azevedo DM, Miranda FAN. Teoria das representações sociais e ALCESTE: contribuições teórico-metodológicas na pesquisa qualitativa. Sau. \& Transf. Soc. [Internet] 2012; 3(4) [acesso em 06 jan 2015]. Disponível: http://www.redalyc.org/ pdf/2653/265324588003.pdf

10. Coutinho NPS, Tavares MCH. Atenção ao paciente renal crônico, em hemodiálise, sob a ótica do usuário. Cad. Saúde Colet. [Internet] 2011; 19(2) [acesso em 09 jan2015]. Disponível: www.iesc.ufrj.br/cadernos/ images/csc/2011_2/artigos/csc_v19n2_232-239.pdf

11. Beuter M, Muller LR, Brondani CM, Pauletto MR, Timm AMB, Perlini NMOG. A adesão de indivíduos em terapia hemodialítica. R. pesq.: cuid. fundam. online. [Internet] 2013; 5(2) [acesso em 10 jan 2015]. Disponivel: http://dx.doi.org/10.9789/2175-5361.2013. v5i2.3558-3566

12. Patat CL, Stumm EMF, Kirchner RM, Guido LA, Barbosa DA. Análise da qualidade de vida de usuários em hemodiálise. Enfermería Global. [Internet] 2012; (17) [acesso em 10 jan 2015]. Disponível: http://scielo. isciii.es/pdf/eg/v11n27/pt_clinica4.pdf

13. Branco JMA, Lisboa MTL. Adesão de clientes renais crônicos ao tratamento hemodialítico: estratégias de enfermagem. Rev. enferm. UERJ. [Internet] 2010; 18(4) [acesso em 10 jan 2015]. Disponível: http://www.facenf. uerj.br/v18n4/v18n4a13.pdf

14. Brasil. Constituição da República Federativa do Brasil. Brasília: Senado; 1988.

15. Fiuza PB, Fernandes MV, Verde FAL, Verde FA. Perfil da doença óssea no paciente com Insuficiência Renal Crônica em hemodiálise. Nutrire [Internet] 2011; 36 [acesso em 22 de julho de 2015]. Disponível: http://www.revistanutrire.org.br/articles/view/ id/4fc383871ef1fad44f000010
Backes VMS. Percepções e mudanças na qualidade de vida de pacientes submetidos à hemodiálise. Rev. Bras. Enferm. [Internet] 2011; 64(5) [acesso em 11 jan 2015]. Disponível: http://www.scielo.br/pdf/reben/v64n5/ a06v64n5.pdf

17. Nepomuceno FCL, Júnior IMM, Silva EA, Lucena KDT. Religiosidade e qualidade de vida de pacientes com insuficiência renal crônica em hemodiálise. Saúde em debate. [Internet] 2014; 38(100) [acesso em 12 jan 2015]. Disponível: http://www.scielo.br/pdf/sdeb/ v38n100/0103-1104-sdeb-38-100-0119.pdf

18. Silva EA, Júnior IMM, Nepomuceno FCL, Lucena KDT, Deininger LSC. Atitude religiosa: uma esperança de cura para os doentes renais crônicos no serviço de diálise. Rev. enferm. UFPE online [Internet] 2014; 8(8) [acesso em 12 jan 2015]. Disponível: http://www. revista.ufpe.br/revistaenfermagem/index.php/revista/ article/view/6063/pdf_5818

19. Araújo CP, Bordignon JS, Lasta LD, Farão EMD, Heck TW, Ferreira EM. Insuficiência Renal Crônica: um enfoque na prevenção do problema emergente no Brasil. Rev. Contexto\&Saúde [Internet] 2013; 11(20) [acesso em 12 jan 2015]. Disponível: https://www. revistas.unijui.edu.br/index.php/contextoesaude/ article/view/1729/1432

20. Barreto MS, Marcon SS. Doença Renal Crônica: vivências e expectativas do cuidador. Rev. enferm. UERJ. [Internet] 2012; 20(3) [acesso em 17 dez 2014]. Disponível: http://www.e-publicacoes.uerj.br/index. php/enfermagemuerj/article/view/2193/2886

21. Grasselli CSM, Chaves ECL, Simão TP, Botelho PB, Silva RR. Avaliação da qualidade de vida dos pacientes submetidos à hemodiálise. Rev. Bras. Clin. Med. [Internet] 2012;10(6) [acesso em 17 jan 2015]. Disponível: http://files.bvs.br/upload/S/1679-1010/2012/v10n6/ a3185.pdf

22. Madeiro AC, Machado PDLC, Bonfim IM, Braqueais AR, Lima FET. Adesão de portadores de insuficiência renal crônica ao tratamento de hemodiálise. Acta paul. enferm. [Internet] 2010; 23(4) [acesso em 01 set 2014]. Disponível: http://dx.doi.org/10.1590/S010321002010000400016

23. Silva AS, Silveira RS, Fernandes GFM, Lunardi VL, Backes VMS. Percepções e mudanças na qualidade de vida de pacientes submetidos à hemodiálise. Rev. Bras. Enferm. [Internet] 2011; 64(5) [acesso em 11 jan 2015]. Disponível: http://dx.doi.org/10.1590/S003471672011000500006

24. Medeiros AJS, Medeiros EMD. Desafios do tratamento hemodialítico para o portador de insuficiência renal crônica e a contribuição da enfermagem. REBES [Internet] 2013; 3(1) [acesso em 28 jan 2015]. Disponível: http://www.gvaa.com.br/revista/ index.php/REBES/article/view/2074/1619 